\title{
Insurance Culture in China Under the Conditions of Transformation
}

\author{
Tang Yuan-xiong \\ Lanzhou University \\ Chen Wen-jiang \\ Lanzhou University \\ Huang Chao \\ Lanzhou Institute of Technology
}

\begin{abstract}
Since reestablished in 1980, as a product of market economy, China's insurance industry has achieved great accomplishments. However, comparing with the commercial insurance in the Western, there are some different characteristics between China and the Western countries. Chinese people have their own understanding of insurance according to their knowledge of insurance. Chinese attitudes towards insurance are less positive. For those Chinese who have purchased commercial insurance, their insurance behavior displays the influences of culture. Facing insurance-one method of dealing with risks, Chinese people like to compare it with the traditional mode of dealing with risks which is composed of family, human relationships, and work unit (State), which cultural foundation is the traditional values including "loyalty, filial piety, and ties of friendship". China's insurance industry still encounters the problem of the low acceptance rate among Chinese people. But due to the social transformation in China, China's social structure has been changing which causes the cultural change. Cultural change brings opportunities for the development of commercial insurance in China.
\end{abstract}

\section{INTRODUCTION}

China has experienced more than 30 years of reform from planned economy to market economy since 1978, and China's reform pushes it into a transformation from agrarian society to industrial society or from Gemeinschaft to Gesellschaft.

During the process of transformation, as a product of market economy, China's insurance industry has developed rapidly, and achieved great accomplishments since its reestablishment in 1980 along with the rapidly economic development. It develops with a high increase rate. For instance, the total insurance premium of all insurance companies was up to $¥ 1420$ billion in the first 11 months of 2012, an increase of 7.44\% from 2011 (Zhu, 2013), and this increased almost ten times from 1999 to 2009. Therefore, China's insurance, which is regarded as the "rising-sun industry" in the twentieth-first century, attracts more than 100 foreign insurance companies come to China to invest (Sun, 2000, p.1). Among them, 40 insurance companies have formally started operation so far (Wang, 2004). Up to the end of 2009, there are 8 insurance group companies, 121 insurance companies and 10 insurance asset management 
companies. These facts indicate that China's insurance has huge potential to develop.

Yet, while the overall assets of the insurance industry are up and the number of market players and the amount of premium incomes are on the rise, the vast majority of Chinese people have not embraced this "insurance culture". For example, the insurance density, or per capita premiums, reflects a country's per capita payment level on insurance premiums, which mirrors the level and quality of insurance guarantees for its people, and also the acceptance of insurance. In 2002, the average rate of premium in the GDP of the world was $8 \%$. China, with its average rate of premium of $3 \%$ ranked $48^{\text {th }}$. In 2009 , the average rate of premium in the GDP of the world was $7 \%$ while China was $3.4 \%$. This data shows the low acceptance rate of commercial insurance in China to some extent.

What's more, China's premium income statistics have been exaggerated (Hao, 2004). For example, according to the China Insurance Regulatory Commission (CIRC), the country’s top insurance industry watchdog, China’s premium income reached $¥ 388.04$ billion (US\$46.8 billion) in 2003, with ¥301.1 billion (US\$36.3 billion) coming from personal insurance, up 32.4\% year on year. However, considering other factors, such as premiums from participating insurance products, premiums from universal life insurance and link investment-oriented insurance, the real insurance density would be adjusted down to ¥156.77 (US\$18.9) (Hao, 2004).

According to the data from Insurance Association of China (Lu, 2002), urban areas are the main market of insurance today, but even in the 46 biggest cities, only $25.6 \%$ of urban resident families have the experience of buying commercial insurance. As for the individual, the rate of individual policies is much lower than that of family policies ( $\mathrm{Lu}, 2002)$. In addition, the survey was conducted in the 46 biggest cities, so the corresponding rate would be lower in smaller cities and towns. However, even in the 46 biggest cities, $26.2 \%$ of urban residents do not believe in commercial insurance. In the countryside, commercial insurance purchase is extremely low (Zhou \& Chen, 2004). Therefore, Wu Dingfu, the former president of China Insurance Regulatory Commission, argues that China's insurance is not accepted well by the people and the nation.

The facts mentioned above imply China's low acceptance rate of commercial insurance. What factors account for this? Most researchers (Yu \& Guo, 2003; Wu \& Lin, 2003; Sun, 2003; Wang \& Li, 2003 ) only analyze this problem in terms of economics. Some researchers (Wang, 2000) emphasize the importance of people's insurance awareness. In sociological perspective, people's insurance behavior is not only individual behavior, but also "common behavior" which shares the characteristic of culture. What's more, an important first step to successful global marketing is to understand the similarities and dissimilarities of values between cultures. This task is particularly daunting for companies trying to do business with China because of the scarcity of research-based information (Emery \& Tian, 2010).

Therefore, this research proceeds on the assertion that this phenomenon will not be fully understood unless Chinese insurance culture itself is taken into account. Culture should be paid more attention to, because it provides the legality of coherent way of life in values, ideas and knowledge (Chen, 2003). And analysts know that values are fairly good predictors of behavior. The thesis seeks to understand the low acceptance and use of insurance in China through describing and analyzing the insurance culture in the conditions of transformation.

\section{LITERATURE REVIEW}

Insurance has caused wide public concern because of the reform of social security system, including officials, researchers, underwriters, and ordinary citizens, pay more and more attention to. Therefore, with regard to the low acceptance and use of insurance in China, many researchers have produced a range of views.

Some researchers (Yang, 2002; Lu, 2002; Wang, 2002; Wu \& Lin, 2003; etc.) point out, there is a positive correlation between the increase rate of people's income and the increase rate of buying insurance. For most Chinese people, the level of income is relatively low, but the price of commercial insurance is beyond their financial ability to insure themselves and their families. Although people's lives 
have been dramatically changed over the last decades, it must be admitted that, shortage of funds is still the one of the biggest questions that they cannot buy insurance. Also, some researchers (Yu \& Guo, 2003) argue that the positive correlation between the increase of people's income and the increase rate of buying insurance is not very strong, because the increase of income is steady, but the increase rate of buying insurance fluctuates a lot. That is to say, whether Chinese people use insurance or not is related to the level of income, but not completely determined by it.

Some researchers find reasons from China's insurance industry itself. For example, insurance's most important principle is the "utmost good faith", but China's insurance industry breaches this principle to some extent (Ma, 2003; Sun, 2003; Wang \& Li, 2003; etc.); the insurance products provided by insurance companies cannot meet people's needs for insurance, such as providing for the aged, medical care, education, housing, and liability ( $\mathrm{Wu}, 2003)$. They think the incomplete development of China's insurance industry does not make provision for Chinese people to accept insurance.

Some researchers (Wu \& Dai, 2002) claim it can be attributed to the improper monitoring of insurance, the lag of the legal system monitoring insurance, and the imbalance between commercial insurance and social insurance, etc.. This is because of government's policy of insurance.

And some researchers (Wang, 2000; The team of insurance investigation, 2001) also realize that people's insurance awareness is the fundamental force to push the development of insurance, and Chinese people's insurance awareness is not adaptable for the development of insurance.

Also some researchers (Lin, 1995; Wang, 2002) take comprehensive factors into consideration, but they just list those factors mentioned above, and do not emphasize the dimension of culture.

While a number of arguments exist for the low acceptance and use of insurance in China, this paper adds another dimension - the insurance culture. That is, what cultural attitudes about insurance must change before China develops its commercial insurance.

When it comes to insurance culture, some researchers and insurance practitioners think that, insurance culture is the culture related to an insurance company. In a broad sense, insurance culture is the summation of material culture and spiritual culture in the insurance action based on the insurance business; in a narrow sense, insurance culture is the spiritual culture in the development of insurance company (Yi, 2000; Zhuo, 2000). What's more, people often use "insurance culture" in the narrow sense. For example, the basic thought of the magazine "INSURANCE CULTURE" edited by the Association of Beijing Company Culture is that, insurance culture is a commercial company's culture.

And some researchers (Zhang, 2001) refer to the "social insurance culture". They think that social insurance culture is the values and custom related to social insurance.

In conclusion, these analyses of insurance culture have noticed the importance of people in the process of insurance action. However, they haven't emphasized enough that ordinary people represent the principal part of insurance culture. We should emphasize that cultural factors influence the communication and success potential of competition in conducting international business (Tian \& Borges, 2011).

In this thesis, unless otherwise specified, the term "insurance" refers to commercial insurance. Insurance, from the perspective of risk management, is a formal social device for reducing risk by transferring the risks (such as property loss exposures, personal loss exposures, liability loss exposures) of several individual entities to an insurer. The insurer agrees, for a consideration, to pay for the loss in the amount specified in the contract (Tang, 2000, p.8).

In this respect, insurance culture can be people's values about insurance behind their attitudes towards insurance and their insurance behavior. Here, the researchers emphasize the importance of cultural values. Values are ideas about what is socially defined as good or desirable. Ways of life, social relationships and social institutions are dominated and adjusted by values (Wang, 2001, p.128). And it embodies itself in people's everyday life through their attitudes and behavior. In this paper, the researchers will describe Chinese people's knowledge and attitudes towards insurance, and describe Chinese people's insurance behavior. Additionally, the researchers will discuss the values behind their attitudes towards insurance and their insurance behavior under the conditions of transformation. 


\section{METHODOLOGY}

Methodology for a thesis including the type of the research, data collection, processing and analysis is to serve the purposes of a specific research. The purpose of this research is to explain the low acceptance of insurance in China from the view of the current insurance culture in China. Therefore, the researchers will describe Chinese people's attitudes towards insurance and Chinese people's insurance behavior because attitudes and behavior can embody the cultural characteristics. The thesis is regarded as a descriptive and interpretive research.

Qualitative and quantitative approaches are often viewed as opposites, but as one does not exclude the other, studies may contain elements of both. Both research methods offer advantages: quantitative data is often argued to be scientific and credible, while qualitative is more detailed and nuanced. However, they are closely interrelated; quantitative data is based on qualitative judgment, and qualitative data can be described numerically. To better understand the current insurance culture, the researchers chose both qualitative and quantitative approaches. While primarily using a qualitative approach, quantitative analysis is used to complement this study.

The reason for using a qualitative method as the primary approach is that, it is a method that searches deeply for information and tries to find underlying causes to the approach of the problem in question. This kind of information is difficult to quantify, since it involves, for instance, attitudes, values and conceptions, so called "soft data". The insurance culture belongs to such kind of information. While the researchers used quantitative data to supplement this analysis, because it is also useful to describe insurance culture, especially when it comes to people's insurance behavior which could be measured in the form of numbers.

Every researcher collects data using one or more techniques (Neuman, 1994, p.27). Because the gathering of data may be direct or indirect, the researchers also chose both. The researchers used the indirect gathering of data in that there are a number of papers, books, and some existing statistics related to insurance in the literature. This body will be used to understand the current situation of China's commercial insurance, together with the traditional and current insurance culture in China. The researchers can use the literatures to analyze some points of the topic without conducting longitudinal research or comparative research. As the related references and the existing data are only related to their own research topics, it maybe encounters the problems of validity and reliability. As for validity, selection is essential. The researchers chose the top-quality references, and then put the related references into the analyzing framework and used them after logical reasoning to solve the problem of validity. Some of these existing data came from one of the researcher's own which was from the survey on the insurance awareness of China's urban residents conducted in 2002. It is useful for the thesis.

As for direct gathering of data, the researchers chose the method of case interview. Interviews can provide a good insight in people's experiences, opinions, attitudes, values and feelings. Through these case in-depth interviews, the researchers attempted to tease out information about Chinese attitudes towards risk and insurance behavior. It is suitable for this thesis and it avoids limitation of money and time. Although the researchers can't use the information from case interviews to draw arbitrary conclusions, such information at least embodies the current insurance culture in China.

To do case interviews more formally for this research, the researchers concentrated the questions on the main three dimensions with outlines: 1). how people perceive and deal with risks; 2) their attitudes towards insurance; 3 ). their insurance behavior. These three dimensions reflect the insurance culture. The researchers conducted research both in urban and rural areas in different time.

The information collected from case interviews find that, both urban residents and rural residents have many of the same attitudes towards insurance. To some extent, both urban residents and rural residents are "peasants" because of the deep influence of agrarian civilization (Shi \& He, 2001, p.135). As urban residents have much higher exposure to insurance and are the main consumers of insurance (Lu, 2002), the researchers used their information to analyze and reflect much more about insurance culture. 


\section{INSURANCE CULTURE IN CHINA UNDER THE CONDITIONS OF TRANSFORMATION}

People's attitudes towards insurance and insurance behavior are based on their knowledge of insurance. Therefore, this part will firstly describe people's knowledge of insurance, and then describe their attitudes towards insurance and insurance behavior, finally discuss why they form such values about insurance.

\section{Chinese People's Knowledge of Insurance}

As an exotic business, insurance was not a part of Chinese culture in the past. At the beginning of its reestablishment, Chinese people knew little about commercial insurance and had their own understanding of insurance. Many different opinions existed about insurance. For instance, there was a joke about this phenomenon that happened at the beginning of its reestablishment. When an insurance salesman went to sell insurance in a community, some of the residents thought he was the man who sold fuses or strongboxes at the mere mention of "insurance" (Wang, 2000). Some people equated "insurance" with "infelicity", so they refused to meet the insurance salesmen at home or at work. Even in the late 1990s, some people thought it was not cost-efficient to buy commercial insurance because it was not useful. Some people thought that buying commercial insurance was a hazardous or risky activity. After buying insurance, they expect something to happen so that they can claim compensation and make profit. If nothing happens, they count it as a loss. These phenomena were common occurrence during that period (Wang, 2000).

Currently, Chinese people know more about insurance after its reestablishment more than thirty years. There is a popular saying among people whose work is related to insurance: the development of insurance depends on drumbeating. The insurance companies have made a lot of detailed advertisements to let Chinese people know more about insurance through all kinds of approaches, such as advertising on journals, newspapers, TV and radios, leafleting in communities and banks, and so on. The data from Insurance Association of China shows that, journals and newspapers are the primary approaches that urban residents acquaint themselves with insurance (Lu, 2002). According to the survey in 2002, almost every urban resident can name at least one insurance agent and one category of insurance product. Even in rural China, it is common to know insurance, including social insurance and commercial insurance by listening to radio and watching TV. With the exception of advertisement made by insurance agents, the approaches that Chinese people acquaint themselves with commercial insurance come from what their friends or relatives tell them, which is the second main way to know insurance (Lu, 2002). As a woman said:

I did not know about insurance before. Last time, after visiting one of my relatives in Lanzhou, I went back home by bus. The booking clerk charged me more ¥ 1 with the exception of ticket. My relative told me that, it was the fee for insurance. That is to say, you paid $¥ 1$ for the insurance in exchange for $¥ 10$ thousand if there was something wrong with me during the trip because of the bus. Of course, if I arrived at home safely, the insurance got my $¥ 1$. From then on, I know this is insurance, right? (a 56 year-old rural woman)

Insurance, as the name of a business, is gradually circulating among Chinese people. However, most Chinese people only have part general knowledge of insurance. For example, only $6 \%$ of urban families think they know details about insurance business (Lu, 2002). According to the survey in 2002, concerning the specific procedures about how to buy commercial insurance and how to claim for compensation, fewer people know how they operate. Some of them who have bought commercial insurance could not tell the differences between the policyholder and the beneficiary, etc. In general, Chinese people are more and more familiar with commercial insurance, but only have superficial knowledge.

\section{The Attitudes towards Insurance}

Although there are many ideas about insurance in Chinese culture, pure commercial insurance was 
originated from other countries and expanded in China with the process of globalization. In addition, there is a tendency for the world insurance market to become integrative (Zhang \& Zheng, 2000, p.40). As a global business, insurance has its own cultural meanings. Economically speaking, insurance is a financial arrangement to proportion the loss of pure risks. The applicant must pay for premiums by cash. During the process of insurance, everything is calculated by money. In this sense, insurance is a financial relationship between the insurer and the applicant. Legally speaking, insurance is a contractual means of shifting the burden of pure risks through pooling to minimize financial loss. According to the contract, the insured undertake the obligation of paying for the premium in exchange for the right of compensation for specific losses provided by the insurer. In this sense, insurance is a contractual relationship between two parties. Also, the implementation of an insurable contract is limited within the period of coverage. During the period of coverage, the two parties must trust the other side and carry on the items on the policy. Insurance contracts form a special class of contract in that the law requires both parties to them, the insured and the insurer, to exercise the "utmost good faith" towards each other. Consequently, there must be a trust mechanism to ensure the implementation of an insurable contract. What's more, insurance must be based on an independent principal part. The two parties of insurance must be in charge of themselves. In conclusion, there are some basic cultural values behind insurance, such as trust, contract, and individualism and so on.

As an economic system, there is no doubt that insurance has been established in China, which includes insurance company, agent, regulation, law and so on. However, internationally, recognized insurance culture is not easy to completely integrate into the local Chinese environment. Chinese people's attitudes towards insurance attest to this.

With the increase of the knowledge of commercial insurance, some Chinese people's attitudes towards commercial insurance become much more objective. More people consider commercial insurance as the au pair exchange between themselves and insurance agents under the conditions of market economy. The exchange is based on the freewill principle that benefits the two sides as they buy commercial insurance to transfer the risks arising from modernity. To nip it in the bud, buying commercial insurance can provide a certain sense of security. According to the survey in 2002, the view that "buying commercial insurance releases them from worries if something unfortunate happens, and it also provides compensation if there is something unfortunate happened" has been shared by $61.2 \%$ of the interviewees. The rapid development of China's insurance industry partly shows more people realize the function of insurance and accept the principles of insurance.

Meanwhile, Chinese people hold some different attitudes towards insurance whether they buy insurance or not, and whatever their backgrounds are. There are some typical types of attitudes towards insurance in the case interviews as following:

\section{First, insurance is not useful}

Insurance is one of the methods of risk transfer, and it is an effective way of dealing with risks in an economical perspective (Sun, 1996, p.20; Tang, 2000, p.9). However, it is another story in China. Commercial insurance occupies only a small portion of methods of dealing with risks so far. They regard the traditional mode of dealing with risks as more effective than insurance. Many people do not understand clear what are insurable risks, and they connect insurance with all risks but doubt its capability to deal with risks at the same time. Although the traditional mode of dealing with risks is changing, they still influence people's attitudes towards insurance. Some Chinese people do not think insurance is useful. As one man said:

Can insurance make me safe? No, it cannot. If there is some emergency happened, can an insurance company solve problems as quickly as my students or my friends? I am sure my students are much more dependable than insurance companies.... Also I have social insurance and it is enough for me to live on for the rest of my life, I believe, if the society runs as the current logic. (Case4)

From what case 4 said we can see that, when it comes to the methods of dealing with risks, people think insurance plays a less important role. Insurance is only one method among all of that, and it can 
only provide financial compensation for insurable risks. What's more, the policyholder should pay for the premium initially. However, the traditional safety net composed of family, human relationships and work unit, aims at all kinds of risks. And the safety net, without so many formal regulations, could change its forms according to the conditions. It provides not only financial compensation but also emotive support. Chinese people are more familiar with this way of dealing with risks. As insurance is a relative new way of dealing with risks in China, Chinese people know its basic function, but do not regard and use it as the main method of risk transfer.

From what case 4 said we can also see that, as one commercial system, insurance is not as dependable as human relationships in ordinary people's opinion. The operation of insurance depends on some formal procedures. It is a formal system. However, do Chinese people trust such system? This refers to the trust mechanism. Many scholars have researched Chinese trust (Li \& Liang, 2002). Some sociologists divide trust into "system trust" and "personal trust" (Qi, 2003) among them, Luhmann (1979) is the most significant one. Although there are some different opinions on the conditions of these two forms of trust, the basic tendency is that, "system trust" is strengthening and "personal trust" is weakening in China. However, "personal trust" still plays quite an important role in Chinese trust (Qi, 2003). Because China's insurance is not a perfect system, and people are prone to "personal trust", it is normal that Chinese people do not treat insurance as dependable as "human relationship" which is based on "personal trust".

\section{Second, insurance limits freedom to some extent}

As mentioned above, insurance is a contractual relationship between two parties. However, not all Chinese people can understand this. Some Chinese people think that an insurance contract is too unkind and unreasonable. As a woman said:

I know how insurance runs. But I do not accept it. The insurance contracts are so complicated. You feel dizzy when reading this or that regulations, items...If I buy insurance, I will have to be limited by the items of policy. My freedom will be lost. What's more, all the items have been designed well before you buy it. So obviously, the insurance contracts are propitious to the insurance company. What is the most important, the management of insurance costs the money from the insurants! (Case5)

China is transforming from a planned economy to a market economy. A market economy is essentially a contractual economy which emphasizes norms (Yan, 2002). Insurance is a part of the market economy and is based on a contract. The relationship among people is also gradually transforming from informal to formal. However, in China, because of the influence of tradition, ethical relationship still influences people. Ethical relationships emphasize people's personal integrity and self-discipline (Qiu, 1995). Chinese people pay much attention to "a promise that will be kept". If you do things by signing contracts and have lawyers, along the way, it means trust is lost and one turns to the legal system to dissolve disputes. Chinese people are not familiar with this new culture. So Case 5 shows that, this woman does not like the insurance contracts.

\section{Third, insurance is not as good as savings or some other way to gather money}

With the development of insurance, insurance companies have designed more and more categories of insurance products to attract people (Wang, 2002). Among them, deposit insurance is a relatively new one that has both the function of insurance and savings. However, Chinese still cannot treat insurance as the same as savings, even some other way to gather money. As a woman said:

In fact, insurance is one method of pooling money to give one individual to use. So why I go to buy insurance and let it restrict me? If I had money, I would like to deposit it into banks. So I can draw it whenever I want...I am too poor to buy insurance or deposit money into banks....Do you know how we pool money? Some people whose situations are like mine, make an alliance. There are 10 persons now and some other people will join us later. We know each other well. Each one in our alliance deposits $¥ 300$ together every month. So we have $¥ 3000$ together every month and then draw 
cuts to decide who can get the whole money that month. We do this by turns. It is a good way to collect money. It is better than insurance. If there is something urgent happening to me, I can apply for the money that month without the limitation of turn. The other people can understand and agree. But I cannot do this if I buy insurance.... (Case6)

From what Case 6 said we can know that, when people decide how to deal with their disposable money, Chinese people would like to deposit their money into banks primarily (Lu, 2002; Yan, 2003), not to buy insurance. Even in the biggest 46 cities, only $9 \%$ urban residents would like to invest their money in insurance, behind the other investments, such as housing, education ( $\mathrm{Lu}, 2002)$. In 2002, the total premium accounted for $3.5 \%$ of the balance of saving deposits of Chinese people, which was lower than the average rate of that- $7.4 \%$-among all the countries in the world. Also, more than $40 \%$ of the purposes of saving are for providing for the aged, education, diseases, and accidents, which is performed by insurance in developed countries (Wu, 2003). Currently, insurance cannot replace savings for potential losses because Chinese people have strong idea that "savings have priority". Therefore, no matter if the external factor is inflation or the bank's adjustments of the interest rate of deposits, they cannot influence the increase of the propensity to save (Fan, 2000). Consequently, insurance is in a subordinate position when people decide how to deal with their money.

\section{Forth, insurance is a deceptive business}

What people talk most is the dishonesty of the insurance agents whenever the researchers conducted survey in 2002 or interviewed people in 2004. Insurance's primary principle is "utmost good faith"; however, Chinese people think that they have breached their primary principle because of the influence of some dishonest events in the realm of insurance. Some people regard insurance as a deceptive business. As many researchers (Ma, 2003; Sun, 2003; Wang \& Li, 2003; etc.) argue, there is, for some, a crisis of trust in the realm of insurance in China. As a man said:

There are so many insurance agents nowadays. You would see them almost everywhere.

But can you trust them? I doubt that. I am working for a foreign company now. The job is not steady-going, although its salary is relatively high in Lanzhou. I once planned to buy insurance; however, I cannot trust any insurance. It is said that, the agents are so enthusiastic to you before the deal has been done; but after you buy the insurance, they will not care for you at all. Some agents even do not tell you under what conditions you cannot get the compensation. Especially when you have to claim settlement, you are swamped in the mud.... (Case7)

As for the insurer, the purpose of dealing in risks with commercial patterns is to profit as well as transfer potential losses for the insurants. Chinese people are familiar with the commercial patterns after carrying out the opening and reform policy, so it is normal for Chinese people to understand that insurance is a profitable business. However, China's insurance is only at the beginning and there have been many deceptive practices between the agents and the insurants (Wang \& Chen, 1999). The incomplete development of insurance makes Chinese people think that, insurance only pays attention to the profit. Therefore, they will think out some substituting way to deal with the potential losses, such as the way Case 6 mentioned: she, with some acquainted people, sets up an alliance to gather money to prepare for something emergent.

There are also some other attitudes towards insurance. These attitudes could display that Chinese people have their own understanding of insurance. Chinese people would like to compare insurance with some other ways of transferring risks, or negatively evaluate insurance according to their own understanding and situation. As mentioned above, insurance has its own basic cultural values when it expands in the whole world during the process of globalization. However, when it arrives in China, insurance encounters the force of locality. As Tomlinson states, "in a huge range of particular customs and predilections-from religious traditions to the attachment to local types of bread or beer-people demonstrate the countervailing cultural force of the local situation" (Tomlinson, 1999, p.88). 


\section{Insurance Behavior}

\section{Social Insurance VS Commercial Insurance}

So far urban areas have been the main insurance market in China and this would be the case for a long time (Lu, 2002; Yu \& Guo, 2003). The rate of rural residents who own any insurance is quite low (Zhou \& Chen, 2004), and few buy commercial insurance. We do know that urban residents are the main consumers of insurance. As for the families, data shows that among urban residents in the 46 biggest cities, $46.5 \%$ of them own at least one kind of social insurance; $4.5 \%$ of them buy at least one kind of commercial insurance; $21.1 \%$ of them own both social insurance and bought commercial insurance; and $27.9 \%$ of them have no insurance. As for the individuals, the rate of individual ownership of insurance is much lower than that of family's ( $\mathrm{Lu}, 2002)$. It could be supposed that the insurance ownership rate would be lower in smaller cities and towns.

From the data above, we can see that, social insurance is more popular than commercial insurance. Not only do more people own social insurance, but also when they have a chance to make a choice, more people choose social insurance than commercial insurance. When asking whether to insurance or not within the following 3 years, $49.9 \%$ of urban residents in the 46 biggest cities replied that were possibly going to buy insurance, including social insurance and commercial insurance. Among them, 51.9\% planned to buy social insurance, $27.6 \%$ thought buying of commercial insurance, and $20.5 \%$ plan to purchase both (Lu, 2002).

Why do more people choose to buy social insurance? Besides the basic factors, such as the early operation of social insurance, and the government policies of compulsory purchase of social insurance by employers for employees ( $\mathrm{Lu}, 2002)$, the cultural values also plays a very important role in consumer's decision. People think that the government is more dependable than a commercial company (Chen, 1996, p.194). This is one kind of trust. According to Luhmann (1979), trust is divided into two types, including "system trust" and "personal trust". Each trust can have multiple subdivisions. When concerning special structures of each trust, there will be one kind of trust being the position of "primary trust" (Qi, 2003). Although trusts of social insurance and commercial insurance belong to "system trust", more people would regard social insurance as "primary trust" since it is carried out by the government. As a man said:

How could I trust commercial insurance? My nephew has bought health insurance for his son. The little boy once caught an acute disease, my nephew sent him to a hospital. After that, he went to insurance company to ask for compensation. But the insurance company refused him because he did not send his son to the hospitals which they designate! ...As for me, I have social insurance. I can depend on it to spend my rest life. Social insurance is absolutely better than commercial insurance. (Case9)

\section{No. 1 Choice: Life Insurance}

As mentioned above, in 2002, the total insurance premium of all insurance companies was $¥ 305.3$ billion which represents an increase of $44.3 \%$ from 2001. Among the total insurance premium, the life assurance was $¥ 195.7$ billion, the premium of health insurance and accident insurance was $¥ 31.8$ billion, and the property insurance was 77.8 billion. Also during the period from January to June in 2003, the total insurance premium of all insurance companies was up to $¥ 212.61$ billion. Similarly, among them, the life assurance was $¥ 165.26$ billion which increased 39.3\% from the same period in 2002, and the property insurance was $¥ 47.35$ billion which increased $11.8 \%$ from the same period in 2002(Mao \& Liu, 2003). From this official statistics, we can see a basic fact that life insurance is the No. 1 people choose to buy nowadays.

The data shows that, the main forms of commercial insurance which Chinese people buy are life insurance, health insurance, accident insurance, and property insurance. After the reestablishment of the commercial insurance industry in 1980, Chinese people had the tendency to pay much more attention to property or substance than people themselves up to 1997 (Shi \& He, 2001, p.131). However, the situation changed at the end of 1997 because the rate of life insurance in the total insurance premium increased to $55.5 \%$, which for the first time, was more than the property insurance. Until June 2003, the rate of life 
insurance of the total insurance premium was up to $77.7 \%$ (Mao \& Liu, 2003). This data displays the change of Chinese people's insurance preference. Now there is a popular value among Chinese people: human being is more important than anything else. As a man said:

My family has a car bought by my wife. She is a vice president of a real estate agent, so she often drives here and there. When she bought the car, she only bought insurance for the car. An accident once happened when she was driving. She was injured, and the car was damaged. The insurance company came to make a compensation on the car, but she had to pay for her fee-for-service by herself. Since then, she bought an accident insurance for herself. And I also asked her to buy accident insurance for herself. Thinking that, if there is something wrong with her, what's the use of the car? (Case8)

\section{Main Insurants of Commercial Insurance: Children and the Elderly}

As mentioned above, life insurance has become the number one insurance Chinese people purchase. According to the principle of life insurance, the one who contributes most to a family should be the insurant of life insurance. However, children are always the first objects chosen for being the insurants of life insurance, and the elderly are the second objects in China. The middle-aged people, who are the policyholders, seldom buy life insurance for themselves. Children and the elderly are the main insurants of commercial insurance in China (Shi \& He, 2001, p.131). Some other surveys draw the same conclusion. For example, in Wuhan, the capital of Hebei Province, 32.05\% of interviewees would like to buy insurance for their children at first, and then $31.90 \%$ for their parents (The team of insurance investigation, 2001). During the process of investigation, the researchers, together with the other investigators, also experienced this concerning who is the first insurant in a family.

For example, some parents buy accident insurance for their children, but not for themselves. The Ministry of Education of China forbids the schools to buy accidental insurance for their students through mandatory purchase since 2003. Therefore, some insurance companies send their salespersons to primary schools to sell the student accidental insurance at the beginning of a new term. When we were conducting surveys about the healthy security of students at the beginning of autumn term in 2003, we saw many parents who had initiatively bought the student accidental insurance for their children. When we asked them whether they had bought insurance for themselves, most of them said "no". Some parents think they are mature enough to avoid risks in daily life, but their children are too young to be responsible for themselves. What's more, because of the family planning policy, most families have only one child. Consequently, children are the focus of the family since they represent the hope of the families. They would like to make sure that their children are safe and under a certain security system in case there is something wrong with them. As a man said:

What do you live for? For Children! Nowadays every family has only one child. In case there is something wrong with the child and I have not enough money, what should I do? How can I live without my child? So it is normal to buy insurance for my child. You are not married. You cannot understand this. (a 35 year-old man in Chengdu)

From the data and case interviews, it can be seen that the traditional values-"respecting the elderly and loving the young" and "to bring up sons is for providing for the aged"-still influence people's activities, such as the choices of the insurants, even if they have been influenced by the increase of individualism during transformation from Gemeinschaft to Gesellschaft.

Chinese people's insurance behavior shows that, they trust social insurance more than commercial insurance, and they pay much more attention to themselves than before, what's more, children and the elderly are the main insurants of commercial insurance. These characteristics partly display Chinese people's insurance behavior that is directed by their cultural values.

\section{DISCUSSION}

Insurance is about providing security, but it is actually parasitic upon risk and people's attitudes towards it. Chinese people's attitudes towards insurance and insurance behavior demonstrates the 
influence of Chinese culture, because Chinese people always put insurance into a cultural environment or a certain relationship to understand and deal with. Why have they formed such attitudes towards insurance and insurance behavior? There are cultural values behind them to dominate, such as "to bring up sons is for providing for the aged" and "savings have priority". These values are not only about insurance, but also about the other methods of dealing with risks and how to obtain a sense of ontological security. Therefore, when people face insurance, they would like to use these values to compare insurance with the related methods of dealing with risks. Culturally speaking, these values are rooted in how Chinese people perceive and deal with risks because insurance is one method of risk transfer.

\section{The Brief Discussion of Risk in a Sociological Perspective}

In economists' opinion, risk can be divided into two types according to its nature: speculative risks and pure risks. Speculative risks are exposures that can result in gains or losses; pure risks can result only in losses (Zhang \& Zheng, 2000, p.4). What insurance deals with is the "insurable risks" of "pure risks" and provides financial compensation for specific losses in exchange for a periodic payment.

However, risk is not that simple in sociologists' eyes. Additionally, ordinary people are not economical persons, but also social persons at the same time. Consequently, there is need reconsidering the notion of risk in a sociological perspective.

When it comes to risk in sociological perspective, the researchers focus on Giddens and Beck, because they are the most outstanding two theorists who have examined risk (Huang, 2004).

Giddens states, "risk originally had an orientation to space. Later, it became transferred to time, as used in banking and investment - to mean calculation of the probable consequences of investment decisions for borrowers and lenders. It subsequently came to refer to a wide range of other situations of uncertainty." According to the history of acceptance of risk, Giddens points out, the idea of risk has always been involved in modernity. "One of modernity's main features is the acceleration of change. This acceleration of change results from the development of expert systems - understood as technological or knowledge systems that organize large areas of the material and social environment in which we live. The central role of expert systems in modernity means that the risks, conscious or unconscious, that social action carries increase. First, there is a transformation in the character of risk. Risk becomes greater and grows unconnected from local conditions. Moreover, it is increasingly socially created. Second, the perception of risk and the perception that the risks attached to expert systems are unpredictable increase because of the greater degree of reflexivity that characterizes modernity"(Diez-Medrano, 2004). So, Giddens argues that risk assumes a new and peculiar importance in the current period because modernity is a risk culture.

Similarly, Beck writes: "Risk may be defined as a systematic way of dealing with hazards and insecurities induced and introduced by modernization itself". Like Giddens, Beck also analyzes risk in the condition of modernity. Beck posits that we find ourselves in the early stages of a new modernity, in which reflexivity plays a major role (Diez-Medrano, 2004). In the new modernity, the central issue is risk and how it can be prevented, minimized, monitored, or managed" (Ritzer, 2004, p.149). Beck also points out, the notion of risk moves through two stages: "in the first instance, risk seems no more than a part of an essential calculus, a means of sealing off boundaries as the future is invaded. Risk makes the unforeseeable foreseeable, or promises to do so. In this initial form, risk is a statistical part of the operation of insurance companies. They know a lot about the secrets of risk which change society, even though nothing has yet happened. This is risk in a world where much remains as 'given', as fate, including external nature and those forms of social life coordinated by tradition. As nature becomes permeated by industrialization and as tradition is dissolved, new types of incalculability emerge. We move then into the second stage of risk, which Giddens and I have called manufactured uncertainty" (Frankin, 1998, p.588).

Both Giddens and Beck argue that, the notion of risk is accompanied by the rise of insurance. Insurance is based directly upon the connection between the idea of risk and the possibility of calculation. However, situations of manufactured risk cannot be actuarial prediction. When risk turns incalculable, insurance becomes impuissant concerning dealing with risks. 
Yet, it does not mean that human beings are being nail-biting facing new risks. As Beck states, "while advanced modernization produces the risks, in also produces the reflexivity that allows it to question itself and the risks it produces. Thus, dialectically, advanced modernity has generated both unprecedented risks and unprecedented efforts to deal with those risks (Riter, 2004, b, p.422). Therefore, like Giddens (Juan Diez-Medrano, 2004) states, regardless of how much ontological security individuals draw from expert systems, they develop optimist, militant, cynical, or pragmatic attitudes towards the risks perceived in these expert systems.

As mentioned above, facing risks, people do not attempt and accomplish nothing, but always try to find ways to obtain a sense of security, and then develop routines to perceive and deal with risks. As Giddens (1998) states, individuals need a certain sense of ontological security and trust. These are obtained from the basic mechanism - a set of daily routines that people are accustomed to and which are integral both to the continuity of the personality of the agent, as he or she moves along the paths of daily activities, and to the institutions of society, which are such only through their continued reproduction. People follow such routines that make it seem as if our lives are safe. However, how to perceive and deal with risks is determined by culture, as risks are fundamentally made up of the perception and definition of culture (Beck, 2002). The risk judgment, including the ways and results of judgment, is quite different in different cultural environments (Lash, 2002). Chinese people have developed their own cultural routines to perceive and deal with risks that they can calculate.

\section{The Perception of Risks under the conditions of Transformation}

On perceiving risks, generally speaking, Chinese people are not sensitive to risks because of the influences of Confucianism which claims tolerance, harmoniousness, domestication, and propriety (Chen, 2000). As an old saying goes: "it is not disaster but good fortune, and it is not possible to avoid disaster", Chinese people were not active to avoid risks in the past as most people believed in fatalism or have the misperceived mentality that risks would not happen to them. As Giddens says: "all previous cultures, including the great early civilizations of the world, such as Rome, or traditional China, have lived primarily in the past. They have used the ideas of fate, luck or the 'will of the gods' where we now tend to substitute risk. In traditional cultures, if someone meets with an accident or, conversely, prospers - well, it is just one of those things, or it is what the gods and spirits intended." Such views do not disappear completely with modernization. They still influence people's perception of risk. For instance, an elder man said:

Are there so many risks? You know, "life and death belongs to destiny, and riches and honor depends on the god". I have experienced so many political movements, but I am still fine! If risks would happen to you, you cannot escape from; if they would not happen to you, even you require, they do not come. (a 76 year-old rural man)

Meanwhile, the world is changing and there are many new risk parameters from modernity which China has involved in. China is inevitably moving into a "risk society" because of the tremendous social transformation. Chinese people have experienced all kinds of risks, including external risk and manufactured risk, such as SARS and "9.11". Facing the new environment, Chinese people are more aware of risks ( $\mathrm{Li}, 2004)$. According to the survey conducted in 2002, more than $80 \%$ of urban residents are aware that risks exist everywhere. As a woman said:

It is so dangerous to live in the current world. See, when you go out to work, the traffic is not good and maybe you are involved in a traffic accident. When you go to entertain at some recreational places, it is heard that some abnormal people who have caught a certain infectious disease, especially AIDS, would inject some liquor of infectious disease up to no good when you are unaware of them. And the food. You have to eat every day. I once bought some vermicelli, but someone told me that they are fumed by sulphur. I used to buy the salad oil from America, but some experts on the TV say, the salad oil is made of GM soybean. And the scientists cannot tell us whether the GM food is safe or not now.... (Case1)

Due to the double process of modernization and systematic transformation, modern China is 
confronted with multiple risks. Therefore, Chinese people perceive not only external risk, but also manufactured risk. After experiencing risks, ordinary people are much more aware of the existence of risks and their perception of risks is much active, even in rural China especially after the crisis of SARS. In $2002,74.1 \%$ of them had measures or savings to deal with the contretemps according to the survey. Therefore, insurance, as one method of dealing with risks, is possible to enter people's life horizon.

\section{China's Traditional Mode of Dealing with Risks and Changes}

There is one outstanding characteristic about how Chinese people deal with risks: risks are always put into one kind of cooperative relationship to prevent, reduce and transfer (Chen, 1996, p.251). Among all kinds of cultural values, there are three core values - "loyalty, filial piety, and ties of friendship" in China's traditional culture which are the principles of all kinds of relationships between individuals and individuals, individuals and groups, or groups and groups (Wang, 2002, p.398). These values are displayed in all personal affairs and interpersonal affairs, including birth, marriage, aging, illness, and death, as well as insurance etc. When Chinese people encounter routine life events, such as birth, aging, death, etc, or any kind of natural or man-made disasters, they turn to these three values that they obey and put into practice. Family, human relationships and work unit (state), which consist of all kinds of relationships, are the carriers of these three values. Based on these values, Chinese people have developed their own traditional mode of dealing with risks which is a safety net composed of family, human relationships, and work unit.

In western societies, the individual is the basic unit of a society, but in China, family is the basic unit (Chen, 2000). For Chinese people, he or she is not an independent individual but one who belongs to a family. As a primary group, the family plays a key role in personal life events. Multiple functions are performed by a traditional Chinese family: economy, reproduction, socialization and support of children, education, religion, and politics (Deng \& Xu, 2001, p.77-78). Naturally, family also has the function of dealing with risks.

The value of "filial piety", which is the core of family ethics(Deng \& Xu, 2001, p.98), makes people safe in the kinship. The value of "filial piety" requires people support their parents as "to bring up sons is for providing for the aged". When they are young, Chinese people not only bring up children but also support their parents, even their elders. Similarly, when they become old, their sons and daughters-in-law would support them. As a famous old saying goes: "sonlessness is the worst among those three unfilial conducts", if a Chinese family has sons, the traditional form of providing for the aged can flow down from generation to generation. Based on this tradition, Chinese people are protected from birth to death by the family, including extended family and family network (Deng \& Xu, 2001). Consequently, family members are the ones Chinese people trust most (Li \& Liang, 2002). In a word, family is the "kernel stronghold" that resists all kinds of risk.

"Human relationships" are very important for Chinese people because "human relationships" are the third methods of resource redistribution in addition to government and market in China (Ren, 2002). Besides family and relatives, the other people, such as friends, who are in the structure of Chinese "human relationships", play a very important role in one's personal life. When Chinese people evaluate a person, one important standard is to see whether the person has the character of "ties of friendship" or not. If a person were regarded as one who does not have the characters of "ties of friendship", he or she would be excluded from certain group memberships. This places the person in a dangerous position because that means the person loses "human relationships" but Chinese Society is based on "human relationships"( $\mathrm{Li}$ \& Liang, 2002).

"Ties of friendship" demands that people offer volunteer help when the other group members encounter difficulties or risks. As an old saying goes: "one can depend on parents at home while depending on friends go-off", people follow this value and help the other group members and conversely obtain help from them. What's more, Chinese people pay attention to the idea that "courtesy on one side only lasts not long". Therefore, they maintain and strengthen the "safety net" through the process of reciprocity. Consequently, all their relatives and friends become their available social resources. Because of the limit of the time and space, this "safety net" is based on the Gemeinschaft of locality and its 
boundary is limited within their geographical place. When they encounter difficulties or troubles, Chinese people can use their social resources effectively and quickly. The "safety net" composed of "human relationships" is the second most important insurance system inferior only to the family. And this proves that China is a society that fosters complex social networks and they are considered powerful advantage in times of uncertainty(Hancock, etc. 2010).

The work unit is significant for an individual after the People's Republic of China, especially for urban residents. Most people are organized into one specific work "unit" which can offer their rights, membership, legality, and meet their all kinds of needs. The work unit once became the "carrier" of all social life in China (Jiao, 2004).

In addition, the work unit is the source of all kinds of social insurances which are based on the planned economy. The government requires that people should be "loyal" to China, and the government offers protection to its people. At the same time, people fulfill their duty according to the "loyal rule". Because of the government's economic policy, the work unit becomes the provider of social insurances instead of the state, including old-age insurance, unemployment insurance, medical insurance, workrelated injury insurance and maternity insurance. The work unit takes responsibilities for all aspects of its members' life from birth to death. Consequently, people were used to feeling safe under the conditions of such a security system. Therefore, being socialized in the work unit environment, people gradually formed "psychology of the work unit" or some values attached o the work unit (Jiao, 2004). They would like to depend on the work unit. As a woman said:

I have contributed greatly to my work unit. My work unit should be in charge of the rest of my life. The government cannot push us into the market. It is not only my personal thought, but many people are like me. As a doggerel that was popular among us goes: "The (Communist) Party (government) is my mother and the factory (work unit) is my family. If there is something wrong with me, the factory (work unit) should take all the responsibilities." (Case 2)

In a word, work unit is the powerful backup force that deals with risks in the national insurance.

Such mode of dealing with risks in China, including self-insurance from the family, informal "mutual insurance" from "human relationships" and social insurance from the work unit, provide Chinese people with not only financial or material support to deal with risks, but also the sense of ontological security.

\section{Changes of China's Traditional Mode of Dealing with Risks}

However, with the opening and reform policy being carried out, the transformation from a planned economy to a market economy shifts the principal part of risks from the government to the company and the individual. What's more, the systematic transformation from a planned economy to a market economy produces more new risks, such as occupational risks (Sun, 2000, p.12-13). Also the systematic transformation naturally causes the changes of the foundation of the traditional mode.

Firstly, the structure of demography and family structure has been changing because of the family planning policy (Sun, 2000, p.14-15): The family planning policy quickens the coming of an aging society in China. The structure of the family has changed. The nuclear family is the main form of family in China now. And with the increase of average longevity, the middle age people have to take much more responsibility to support the elders, but at the same time, the structure of occupation is changing. Jobs are not stable as before. These changes challenge the force of China's family concerning dealing with risks.

Secondly, the structure of human relationships has been changing because of the systematic transformation, as well as the infusion of ideas from the West (Xue, 2004). The relationship based on the Gemeinschaft of locality and blood has been developing into the independent relationship or the relationship is changing from status to contract; with the increase of population flow, the "acquainted society" has been changing into "stranger society". During the process, consequently, people pay attention to not only "ties of friendship" but also "interests" among human relationships with the development of the market economy because the market economy alters people's ideas about benefit and "ties of friendship". People's lives are much more directly related to the economy. Consequently, people cannot 
feel the same sense of ontological security through all kinds of human relationships as before.

Thirdly, the relationship between the work unit and ordinary people has been changing. According to the requirements of market economy, the work unit will not offer the social insurances to its member independently for free. Today, the fee of social insurance is paid by the individual, the work unit, and the national government together. Also, social insurance can only offer basic living security. The work unit (company) becomes the independent economic entity. The relationship between work unit and its members is inclined to be a contractual obligation and right. The work unit is not like the "second extended family" as before and the roles of people in their work unit become more bureaucratic or turn to be "working people". People cannot find a strong sense of safety from the work unit now.

Because of these changes, Chinese people cannot gain a strong sense of ontological security as before. With the increase of risks under the conditions of transformation, Chinese people have realized that they cannot completely depend on the traditional mode of dealing with risks. Therefore, Chinese people are seeking a new way of dealing with them. With this understanding, insurance, which provides them with a choice of dealing with risks, is developing in China. However, it is only one of the choices of dealing with risks Chinese people face, the cultural values about how to deal with risks have not changed synchronously with the transformation because of the "cultural lag". As for the whole Chinese people, the basic values in Chinese culture have not been a long way off, but they exist in a situation of more illegibility. The ways one gets along with others or takes order with business among Chinese people are controlled by the basic system of values in a not very clear way (Zheng, 1999). This could be embodied through some practical processes. Insurance cannot be excluded this process. Those values make people find more sense of ontological security from the traditional mode of dealing with risks compared with commercial insurance. What's more, the traditional mode of dealing with risks is still operating during the transformation from Gemeinschaft to Gesellschaft. Consequently, Chinese people's attitudes towards insurance and insurance behavior are influenced by these values. In view of the strong influence of cultural values, it is not strange that the acceptance and use rate of insurance is low, and it is not strange that Chinese insurance behavior is different from that of Westerners.

\section{CONCLUSION}

China's transformation from a planned economy to a market economy creates great needs for commercial insurance (Sun,2000, p.12). China's insurance industry has made great accomplishments, but encounters the problem of "choke point"-low acceptance rate of commercial insurance. Chinese people's attitudes towards insurance are less positive but more negative, and their insurance behavior also has their own characteristics. Behind them, the traditional values - "loyalty, filial piety, ties of friendship", which are the cultural foundation of the traditional safety net composed of family, human relationships, and work unit (state), still have deep influence on commercial insurance. Chinese people always compare commercial insurance with the traditional mode of dealing with risks. They regard the traditional mode of dealing with risks as a more effective way than commercial insurance. It is inevitable that this occurs during the process of transformation from Gemeinschaft to Gesellschaft. The low acceptance rate of commercial insurance is from a part of Chinese cultural heritage. Insurance might have forgotten the traditional values, but it seems that the traditional values have not forgotten insurance.

\section{REFERENCES}

Beck, U. (2002). Risk Society Revised. Marxism \& Reality, translated by Hao Weidong, (2), 46-51.

Chen, C. X. (1996). Researches on Social Security and Insurance, Chengdu: Southwestern University of Finance and Economics Press.

Chen, C. X. (2000). How to Understand the Insurance Consciousness of Chinese people, Journal of Zhejiang Finance, (2), 37-38.

Chen, G. (2000). The Revolutions in the Family, Beijing: China Social Science Press.

Chen, X. (2003). Guaranty and Consumption - Current China's Consumerism in Daily Life, Nanjing: 
Jiangsu People Press.

Deng, W. Z. and Xu, R. (2001). Sociology of Family, Beijing: China Social Science Press.

Emery, C. \& Tian, R. K. (2010).China Compared with the US: Cultural Differences and the Impacts

on Advertising Appeals. International Journal of China Marketing, 1, (1), 45-59.

Fan, J. P.(2000). Private Consumption and Economic Development in China, Beijing: China Planning Press.

Feng, X. T.(2001). Sociological Research Methods, Beijing: People's University Press.

Frankin, J. (1998). The Politics of Risk Society, Cambridge: Plity.

Giddens, A. (1998). The Constitution of Society, translated by Li Kang \& Li Meng, Beijing: SDX

Joint Publishing Company.

Hancock, P., Simpson, N. and Rhee, E. (2010).Modeling Uncertainty through Agent-Based

Participatory Simulation: Implication to Businesses in China, International Journal of China Marketing,

$1,(1), 85-95$.

Hao, Y. S.(2004). Premium Bubbles Ringing Alarm Bells, China Daily, November 18, 2004.

Huang, Q.Q. (2004). On the theory of Risk Society and its Practical Meaning, Society, (3), 27-29.

Jiao R.S. (2004). Relationship, Work Unit and Social Transformation, Journal of Xidian University

(Social Science Edition), (2), 138-143.

Diez-Medrano, J. (2004). Questioning Modernity: A Test of Giddens's, Beck's, and Inglehart's

Theories, Internet (2004-12-30): http://www.sscnet.ucla.edu/soc/groups/ccsa/medrano.pdf.

Lash, S. (2002). Risk Society and Risk Culture, Marxism \& Reality, translated by Wang Wulong, (4), 52-63.

Li, L. L. (2004). Social Transition: Risk and Social Control, Journal of Renmin University of China,

(2), 10-16.

Li, W. M. and Liang, Y. C. (2002). Particular Trust and Universal Trust: The Structures and

Characteristics of Chinese Trust, Sociological Research, (3), 11-22.

Lin, Z. J.(1995). The Lag Conditions of China's Insurance Market and its Measurements, China's

Insurance, (2), 6-7.

Lu, R. B.(2002). The results of demands for insurance market in China's 50 cities, INTERNET(2002-

07-03): http://news.xinhuanet.com/fortune/2002-07/03/content_468350.htm.

Luhmann, N. (1979). Trust \& Power, Chichester:Wiley.

Ma, X. B. (2003). On the Inadequacy of Credibility in China's Present Insurance Business, Journal of

Lanzhou University (Social Sciences), (6), 128-131.

Mao, X.P. and Liu, S. P. (2003). The total Insurance Premium of all Insurance Companies was up to

¥212.61 Billion, INTERNET (2004-07-09):http://www.northeast.com.cn/cjnews/80200307090704.htm.

Neuman,W.L. (1994). Social Research Methods: Qualitative and Quantitative Approaches, Allyn \&

Bacon.

Qi, G. (2003). The Trust Reestablish during the Process of Transformation in a Sociological

Perspective, Explore, (5), 81-84.

Qiu, B. (1995). Pandect of Contract, Journal of Jilin University(Social Science), (4), 39-47.

Ren, H. (2002). Summarization of Symposium on China Society under the Conditions of

Transformation, Sociological Research, (2), 123-125.

Ritzer, G. (2004 ). Contemporary Sociological Theory and its Classical Roots: the Basics, Beijing:

Peking University.

Shi, Y. and He, F. (2001). The Safe Exit-The Problem of Insurance, Beijing: China Intl Broadcasting. Sun Q.X. (1996). Introduction to Insurance, Beijing: Peking University Press.

Sun, Q. X.(2000). China's Insurance Industry: Contradictions, Challenges and Measurements,

Beijing: China Finance Press.

Sun, R. (2003). Institutional Analysis on the Lack of Faith in China's Insurance Industry, Insurance

Research, (9), 2-5.

Tang, Y.X. (2000). Theory and Practice of Insurance Agent, Beijing: China Social Science Press.

The team of insurance investigation. (2001). Investigation and Analysis of Wuhan Citizen's Sense of 
Insurance, Journal of Wuhan Polytechnic University, (1), 55-58.

Tian, K. and Borges, L. (2011).Cross-Cultural Issues in Marketing Communications: An Anthropological Perspective of International Business, International Journal of China Marketing, 2(1), $110-126$.

Tomlinson , J. (1999). Globalization and culture, Oxford: Polity.

Wang, C. H.(2002). The History of China's Social Thoughts, Beijing: China People's University Press. Wang, M. F.and Chen, X. (1999). Why Insurance Dissension is increasing, China's Insurance, (12), 33-34.

Wang, N. (2001). Sociology of Consumption — an analytic perspective, Beijing: Social Science Document Publishing House.

Wang, X.L. and Li, A. L. (2003). The reasons and Tactics for the Lack of Faith in the Insurance Market, Journal of Hebei Engineering \& Technology Vocational College, (2), 27-28.

Wang, X. (2000). Strengthen the Insurance Consciousness to Develop Insurance in China, Insurance Research, (3), 1-4.

Wang, X. Z. (2004). The Open Policy Activates China's Insurance Producer Market, Financial News, December 10.

Wang, X. P. (2002). China's Insurance Industry's Condition, Problems and Measures, China newly high Technology Enterprises, (4), 4-11.

Wu, D. F. (2003). Promoting the Innovation of Insurance Theory to Accelerating the Continually

Rapid and Healthy Development of China's Insurance Industry, Economics Science, (5), 5-9.

Wu, J. P. and Dai, J. (2002). The Development Problems of China's Insurance Industry and its Measurements, Jiangxi Social Science, (11), 231-233.

Wu, J. M.and Lin, B. Q. (2003). Positive Analysis on the Models of Insurance Need, Fujian Forum

(Economy and Society), (10), 26-30.

Xue, T. S. (2004). Analysis on the Causes of the Current Trust Puzzledom, Society, (6), 51-53.

Yan, H. (2003). High Saving Rate Influences the Expanding Domestic Demand, China Youth Daily,

May 16.

Yang, S. (2002). The Lack of People's Insurance Awareness' Causes and Measures, Journal of

Guangxi Commercial College, (2), 68-70.

Yan,H. (2002). Contractual Ethic and its Realization, Ethics and Civilization, (6), 30-34.

Yi, X. (2000). Thoughts on Promoting Establishment of "Insurance Culture" in Insurance Company,

Xinjiang Nongken Economy, (1), 60-61.

Yu, D.J. and Guo, N. (2003). Positive Analysis and Policy Meanings of Urban People's Insurance

Demand in China, Journal of Shandong University(Philosophy and Social Sciences), (6), 132-136.

Zhang, H.Z. and Zheng, G. C. (2000). Introduction to Insurance, Beijing: China's People Univ. Press.

Zhang, Y. (2001). On the Social Insurance Culture, Journal of Nanchang University, (1), 66-70.

Zheng, B. (1999). The Trust Relationship between the Superior and the underling in the Corporations, Sociological Research, (2), 22-37.

Zhou, T. and Chen, J. (2004). Conditions and Measures of Rural Insurance Market in China, Finance and Economy, (1), 23-25.

Zhou, T. and Chen, J. (2004). The Current Condition of China's Rural Insurance Market and its'

Countermeasure, Finance and Economy, (1), 23-25.

Zhu, J.S. (2013). Journey with Winds and Rains: Chinese Insurance Industry Back 2012, China Insurance, (1), 17-23.

Zhuo, Z. Q. (2000). Insurance Business Action and the Construction of Insurance Culture, Journal of Theory Field, (5), 24-25.

***Authors' Acknowledgement: We thank the editors and reviewers of IJBA for their critical review comments and constructive suggestions for revision of our paper. And this paper is supported by the Fundamental Research Funds for the Central Universities (No. 13LZUJBWZY059). 